\title{
Low specificity of metal ion binding in the metal ion core of a folded RNA
}

\author{
KEVIN J. TRAVERS, ${ }^{1}$ NATHAN BOYD, and DANIEL HERSCHLAG \\ Department of Biochemistry, Stanford University, Stanford, California 94305-5307, USA
}

\begin{abstract}
The structure and activity of nucleic acids depend on their interactions with metal ions. Fundamental to these interactions is the degree of specificity observed between the metal ions and nucleic acids, and a complete description of nucleic acid folding requires that we understand the nature of the interactions with metal ions, including specificity. The prior demonstration that high concentrations of monovalent cations prevent nonspecific association of divalent ions with nucleic acids provides a novel and powerful means to examine site-specific metal ion binding isolated from complicating effects of the ion atmosphere. Using these high monovalent cation solution conditions we have monitored the affinity of a series of divalent metal ions for two sitespecific metal ion binding sites in the P4-P6 domain of the Tetrahymena group I intron ribozyme. The metal ion core of this highly structured RNA binds two divalent metal ions under these conditions. Despite multiple metal ion-RNA interactions observed in the X-ray crystallographic structure of P4-P6 RNA at the metal ion binding sites, these sites exhibit low specificity among $\mathrm{Mn}^{2+}, \mathrm{Mg}^{2+}, \mathrm{Ca}^{2+}, \mathrm{Ni}^{2+}$, and $\mathrm{Zn}^{2+}$. Nevertheless, the largest divalent metal ions tested, $\mathrm{Sr}^{2+}$ and $\mathrm{Ba}^{2+}$, were excluded from binding, exhibiting affinities at least two orders of magnitude weaker than observed for the other metal ions. Thus, a picture emerges of two metal ion binding sites, each with a high tolerance for metal ions with different properties but also with limits to accommodation. These limits presumably arise from steric or electrostatic features of the metal ion binding sites.
\end{abstract}

Keywords: RNA folding; metal ion specificity; hydroxyl radical footprinting; P4-P6 domain; tertiary structure formation

\section{INTRODUCTION}

Metal ions play critical roles in the structure and function of many biological molecules (Rosenzweig 2002; Babu et al. 2003). They provide structural stability, regulate enzyme activity, regulate structural conformations, and extend the range of chemical functionalities beyond that supplied by the naturally occurring amino acid and nucleic acid side chains (Creighton 1993). The detailed structure of the metal ion binding pockets and the differing characteristics of the bound metal ions can lead to varying stabilities or catalytic abilities with occupancy by different metal ions. Thus, a deeper understanding of metal ion specificity will foster a more incisive understanding of the structure and function of biological macromolecules.

\footnotetext{
${ }^{1}$ Present address: Kevin Travers, Affymetrix, Inc., Santa Clara, CA 95051, USA.

Reprint requests to: Daniel Herschlag; Department of Biochemistry, Stanford University, Stanford, California 94305-5307, USA; e-mail: herschla@stanford.edu; fax: (650) 723-6783.

Article published online ahead of print. Article and publication date are at http://www.rnajournal.org/cgi/doi/10.1261/rna.566007.
}

Much effort has been directed toward identifying and understanding metal ion specificity in nucleic acids. There is an ever-growing number of catalytic RNAs, nearly all of which have been examined for metal ion specificity. The most common method used to demonstrate such specificity has been to measure catalytic activity in the presence of different divalent ions (Guerrier-Takada et al. 1986; Grosshans and Cech 1989; Dahm and Uhlenbeck 1991; Chowrira et al. 1993; Heilman-Miller et al. 2001; Nakano et al. 2003). The information gained from these types of experiments has been enhanced by the ability of some ions to support structural stability but not activity (GuerrierTakada et al. 1986; Grosshans and Cech 1989; Chowrira et al. 1993). For example, metal ion specificity for a catalytic activity can be monitored by maintaining a constant background of one cation that does not support catalytic activity on its own and varying the identity of a second cation that does. Structural approaches, including X-ray crystallography (Cate et al. 1997; Basu et al. 1998; Ennifar et al. 2003), chemical and other footprinting (Celander and Cech 1991; Brannvall et al. 2001; Rangan and Woodson 2003), and native gel electrophoresis (Heilman-Miller et al. 
2001) have also been used to assess metal ion binding specificity in nucleic acids.

But, despite the considerable efforts to examine metal ion specificity in a wide range of nucleic acid systems, numerous challenges remain. In addition to the presence of an often unspecified number of specific ion binding sites, metal ion studies are fundamentally limited by the polyelectrolyte nature of nucleic acids. These limitations and complications render investigation and interpretation of metal ion specificity more difficult and more complex than is the case for proteins, which are less highly charged macromolecules and typically better characterized structurally.

The vast majority of the cations that associate with nucleic acids interact in a loosely bound "ion atmosphere" (Bukhman and Draper 1997; Misra and Draper 1999; Draper 2004); thus, ion binding at specific sites can be obscured by changes in composition of the surrounding ion atmosphere. Further, the polyelectrolyte nature of RNA and the complex structural motifs of RNA create the possibility of multiple ion binding sites. X-ray crystallographic experiments using tRNA (Shi and Moore 2000), the hammerhead ribozyme (Pley et al. 1994; Scott et al. 1995), the P4-P6 subdomain of the Tetrahymena ribozyme (Cate et al. 1997; Juneau et al. 2001), and the group I Azoarcus ribozyme (Adams et al. 2004) have confirmed the ability of metal ions to bind at multiple positions within a single RNA molecule. The observed metal ion specificity, whether measured by effects on activity or through structural effects, represents a complex convolution of effects of metal ions either directly bound to the nucleic acid or associated with the local ion atmosphere. Thus, the observed specificity generally cannot be ascribed to a particular metal ion binding site (Feig and Uhlenbeck 1999).

Here, we take advantage of the structurally characterized P4-P6 RNA domain from the Tetrahymena thermophila group I intron and the recently demonstrated ability to saturate the ion atmosphere with $\mathrm{Na}^{+}$to isolate and probe the binding at two specific divalent metal ion binding sites (Scheme 1; Das et al. 2005b).

\section{RESULTS}

Recent advances have provided a unique opportunity to study the site-specific binding of metal ions without the complications described in the Introduction (Bukhman and Draper 1997; Das et al. 2005b). Das et al. (2005b) took advantage of an extensively studied RNA system, the P4-P6 domain from the Tetrahymena group I ribozyme. Several crystal structures have been obtained for this RNA, revealing two side-by-side stacked segments of RNA helices and noncanonical structures that make tertiary contacts with each other (Fig. 1A; Cate and Doudna 1996; Cate et al. 1996, 1997; Juneau et al. 2001). Within P4-P6 there is a

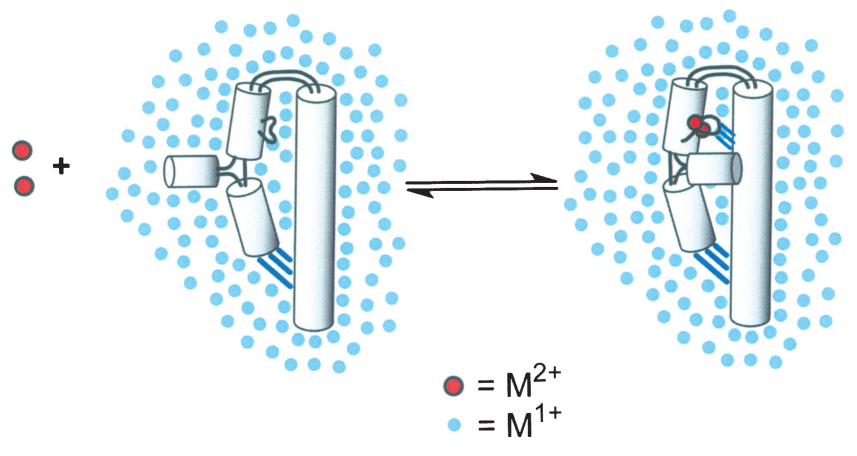

SCHEME 1.

short region of the backbone that undergoes a tight turn. This region has been called the "metal ion core" due to the fact that the close approach of backbone phosphates in this turn appeared, by structural inspection, to be stabilized by the presence of several $\mathrm{Mg}^{2+}$ ions (Fig. 1B,C; Cate et al. 1997).

Placing this or other RNAs in a background of high concentrations of monovalent cations saturates the ion atmosphere, shielding the RNA from the divalent ions that would otherwise make up the ion atmosphere, as depicted in Scheme 1 (Bukhman and Draper 1997; Das et al. 2005b). Thus, divalent metal ion association in the presence of high concentrations of monovalent ions occurs predominantly at specific binding sites (Bukhman and Draper 1997; Das et al. 2005b). P4-P6 RNA in these conditions associates with only two $\mathrm{Mg}^{2+}$ ions (Das et al. 2005b). Subsequent metal ion binding studies with phosphorothioatesubstituted P4-P6 have provided strong evidence for specific occupancy of the two sites depicted in Figure 1, B and C (J. Frederiksen, R. Das, D. Herschlag, and J. Piccirilli, in prep.). Finally, the ability of P4-P6 to fold in high concentrations of monovalent cations, forming all of its tertiary structure except the central metal ion core (Takamoto et al. 2004), allows study of these sites in the absence of coupled large-scale folding events that could complicate metal ion specificity studies. For example, formation of the tetraloop/tetraloop receptor interaction in low salt conditions requires that the P4/P5/P6 helix align with the P5abc structure. This large-scale folding event will also be accompanied by a change in the ion atmosphere (Bukhman and Draper 1997; Draper 2004). In this way, metal ion site binding specificity under low salt conditions is convoluted with changes in the ion atmosphere that are coupled to overall folding (Bukhman and Draper 1997; Draper 2004).

This simplification for P4-P6 RNA in high salt is shown explicitly in Scheme 2, where the formation and stabilization of the site-specific metal binding sites is depicted in two steps. The Scheme does not imply a kinetic pathway, but rather presents a useful thermodynamic breakdown of the metal ion association process. Because the structure 
A

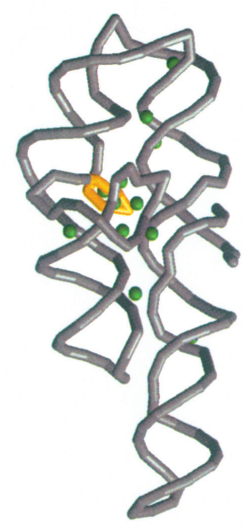

B

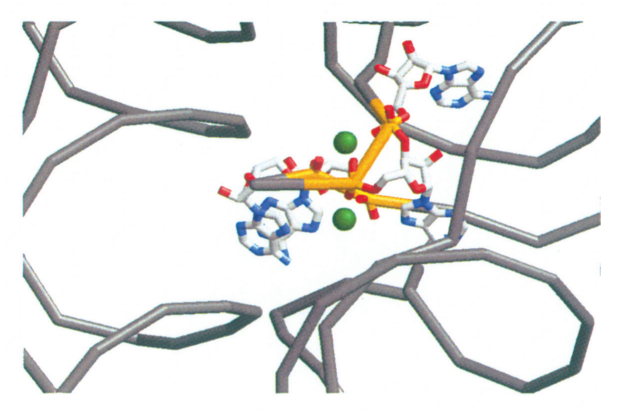

charge density interact less well with the high charge density of the phosphoryl oxygen atoms at the metal ion binding sites.

\section{Probing metal ion specificity in the P4-P6 metal ion core}

As noted above, under conditions of high concentrations of monovalent ions, P4-P6 RNA adopts a nearly native structure, with its tetraloop/tetraloopreceptor interaction formed but lacking a folded metal ion core (Fig. 2A,B; Takamoto et al. 2004). Upon addition of low millimolar concentrations of

C

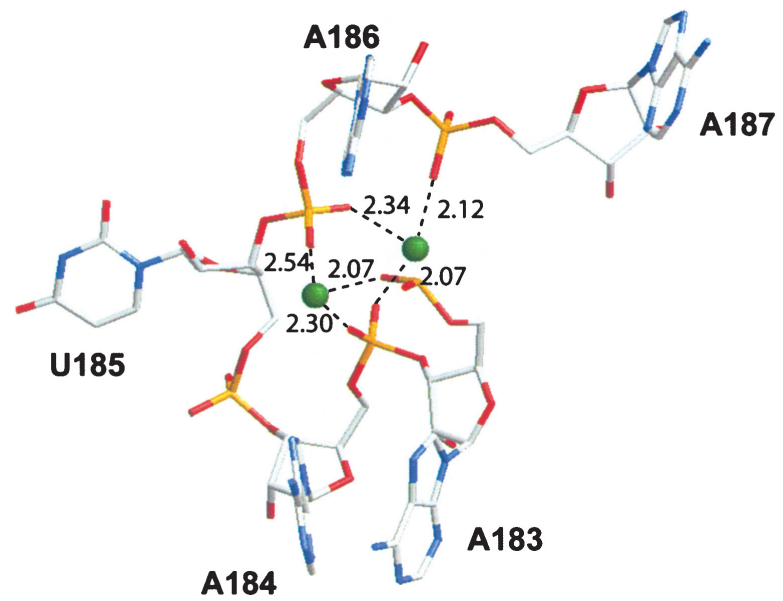

FIGURE 1. Structure of the P4-P6 domain of the Tetrahymena ribozyme. Model shown is based on coordinates from Cate et al. (1996). (A) View of the RNA showing the 12 sites of electron density identified in the model as likely $\mathrm{Mg}^{2+}$ ions (green spheres). The RNA is oriented with the J5/5a hinge at the top and the tetraloop/tetraloop receptor interaction at the bottom (see Fig. 2). The A-rich bulge (orange) is at the back of the molecule in this view. (B) Close up of the metal ion core. The RNA is rotated 180 degrees around the vertical axis in the plane of the page, relative to the representation in $A$, to reveal the tight turn taken by the backbone residues of the A-rich bulge (orange). The residues making the closest approach to the $\mathrm{Mg}^{2+}$ ions are shown as a stick model. Only the two $\mathrm{Mg}^{2+}$ ions thought to be critical to A-rich bulge formation are shown. (C) Residues 183-187 of P4-P6 and the two critical $\mathrm{Mg}^{2+}$ ions (green). The distances between phosphate oxygen atoms and the two $\mathrm{Mg}^{2+}$ ions are indicated in Angstroms next to the dashed lines.

itself is essentially the same regardless of the divalent ion used, the energetic contribution from folding is constant. Thus, differences observed between different ions are expected to reflect differences in binding affinity to the metal ion sites ( $K_{\text {bind }}$ in Scheme 2).

The results presented below show remarkably low specificity of divalent metal ion binding to the two core metal ion sites in P4-P6 RNA. Nevertheless, there are limits to accommodation that may arise from steric features of the metal ion binding sites, such that a size threshold prevents the binding of ions beyond a certain size, or from electrostatic features, in which ions of lower divalent ions, the metal ion core and the entire RNA molecule adopt their native structure, as judged by the onset of a hydroxyl radical protection pattern that is indistinguishable from that obtained in the presence of divalent ions and only modest concentrations of $\mathrm{Na}^{+}$(Fig. 2C,D; Takamoto et al. 2004). Strikingly, the Hill slope observed here for the metal ion core hydroxyl radical protections in a titration with $\mathrm{Mg}^{2+}$ is 2, identical within error to the difference between the number of ions previously observed to bind to the folded and unfolded states using direct ion counting methods (Das et al. 2005b). These results and those of Frederiksen et al. (J. Frederiksen, R. Das, D. Herschalg, and J. Piccirilli, in prep.) indicate that, in these particular solution conditions, the energetic effects of specific metal ion binding can be reasonably isolated from nonspecific ion-nucleic acid interactions and can be followed by hydroxyl radical footprinting.

We therefore used hydroxyl radical footprinting with a constant background of $2 \mathrm{M} \mathrm{NaCl}$, and we followed protection of the metal ion core region as a function of the concentration of

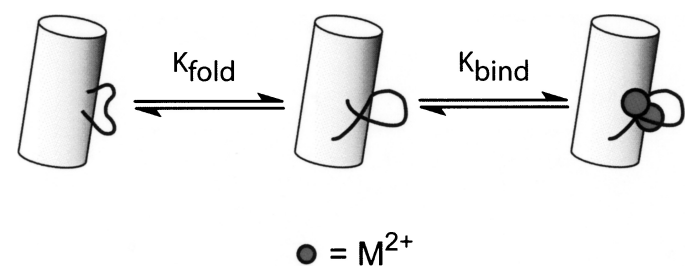

SCHEME 2. 
A
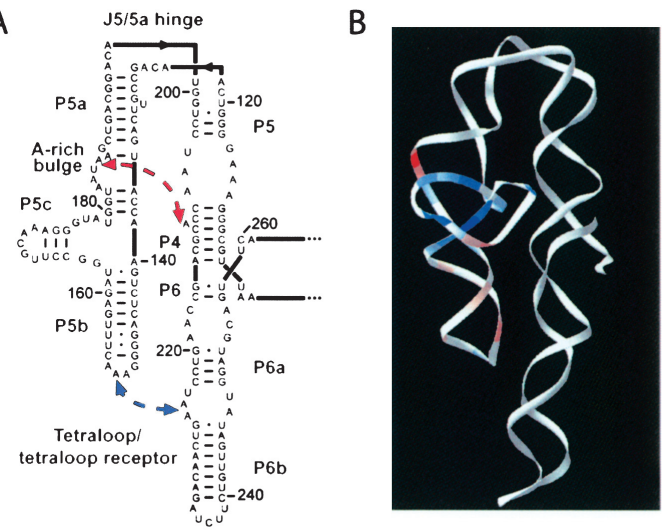

C
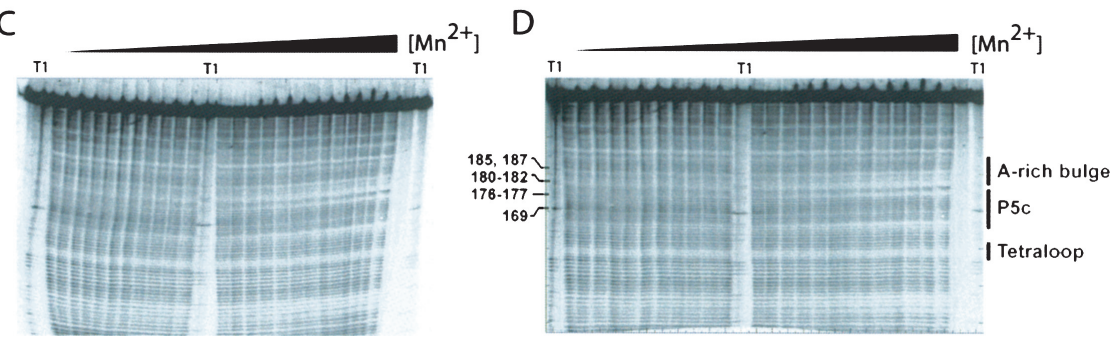

FIGURE 2. Structural changes induced by the addition of $\mathrm{Mg}^{2+}$ to $\mathrm{P} 4-\mathrm{P} 6 \mathrm{RNA}$ in high monovalent salt. (A) Secondary structure depiction of P4-P6. The two main elements of tertiary structure are indicated with colored arrows: (blue) the tetraloop/tetraloop receptor interaction, (red) the interaction between the A-rich bulge and P4. In the presence of $2 \mathrm{M} \mathrm{Na}^{+}$, hydroxyl radical protections occur in the tetraloop but not in $\mathrm{P} 5 \mathrm{c}$ or the A-rich bulge, indicative of structure formation only in the tetraloop. The addition of $\mathrm{Mg}^{2+}$ to this state introduces protections at both the A-rich bulge and P5c sites (Takamoto et al. 2004; Das et al. 2005b). (B) Tertiary structure model of P4-P6, illustrating the structural change upon addition of divalent ions, in this case $\mathrm{Mn}^{2+}$, to P4-P6 in a high salt background. The color indicates changes in protection upon divalent addition: (blue) protection, (red) exposure. $(C)$ A representative hydroxyl radical footprinting gel, which demonstrates the protections present in $2 \mathrm{M}$ $\mathrm{Na}^{+}$but no $\mathrm{Mn}^{2+}$ (the tetraloop protections; left side of gel) and the increase in protection for the A-rich bulge and $\mathrm{P} 5 \mathrm{c}$ as the $\mathrm{Mn}^{2+}$ concentration is increased (left to right). Lanes marked with $T 1$ contain a T1 ladder digest of the P4-P6 RNA, rather than a footprinting reaction, and are used to identify specific residues in the titration. $(D)$ The same gel as shown in $C$, but following SAFA gel rectification (Das et al. 2005a). Residues indicated on the left side of the gel show significant changes in protection across the titration.

a series of divalent ions. The ions used were $\mathrm{Mg}^{2+}, \mathrm{Mn}^{2+}$, $\mathrm{Ca}^{2+}, \mathrm{Sr}^{2+}, \mathrm{Ba}^{2+}, \mathrm{Zn}^{2+}, \mathrm{Ni}^{2+}$, and $\mathrm{Cd}^{2+} \cdot \mathrm{Cd}^{2+}$ and $\mathrm{Zn}^{2+}$ led to degradation of the RNA at concentrations below any observed folding transitions and were therefore not included in the analyses herein. Of the remaining ions tested, addition of $\mathrm{Mg}^{2+}, \mathrm{Mn}^{2+}, \mathrm{Ca}^{2+}$, and $\mathrm{Ni}^{2+}$ led to folding of the P4-P6 metal ion core at low millimolar concentrations, whereas $\mathrm{Ba}^{2+}$ and $\mathrm{Sr}^{2+}$ did not (Fig. 3; Table 1).

For the divalent metal ions for which hydroxyl radical protections indicative of folding could be observed, the resulting patterns of protection were analyzed using semiautomated footprinting analysis (SAFA) (Das et al. 2005a). The metal ion concentration dependencies of the protections were fit to the Hill equation (Equation [1]; $f_{N}$ is the fraction $\mathrm{P} 4-\mathrm{P} 6$ protection, which corresponds to the fraction of P4-P6 in its native state, and $\left[\mathrm{M}^{2+}\right]_{1 / 2}$ is the concentration of the divalent ion $\mathrm{M}^{2+}$ that results in folding $50 \%$ of the molecules). The fits are shown in Figure 3 and give the folding midpoints $\left(\left[\mathrm{M}^{2+}\right]_{1 / 2}\right)$ and the slopes through the transition midpoint $\left(\mathrm{n}_{\mathrm{H}}\right)$ listed in Table 1.

$$
f_{N}=\frac{\left(\left[M^{2+}\right] /\left[M^{2+}\right]_{1 / 2}\right)^{n_{H}}}{1+\left(\left[M^{2+}\right] /\left[M^{2+}\right]_{1 / 2}\right)^{n_{H}}}
$$

For $\mathrm{Mg}^{2+}$ and $\mathrm{Mn}^{2+}$, the value of $\mathrm{n}_{\mathrm{H}}$ was 2, within error (Table 1, $\mathrm{n}_{\mathrm{H}}$ ), consistent with two additional metal ions taken up by the folded molecule relative to the unfolded, as was previously observed and verified for $\mathrm{Mg}^{2+}$ dependent folding (Das et al. 2005b). In the case of $\mathrm{Ca}^{2+}$ or $\mathrm{Ni}^{2+}$, the slope differed slightly from the expected value of 2, perhaps indicative of a small alteration of binding cooperativity. However, in both cases the data could be fit essentially as well with the slope fixed at 2, without altering the $\left[\mathrm{M}^{2+}\right]_{1 / 2}$ significantly (Table 1). For $\mathrm{Sr}^{2+}$ and $\mathrm{Ba}^{2+}$, no folding transition was observed.

The folding midpoints for this series of divalent ions followed the trend $\mathrm{Mn}^{2+}<\mathrm{Mg}^{2+} \approx \mathrm{Ca}^{2+}<\mathrm{Ni}^{2+}<<\mathrm{Sr}^{2+}, \quad \mathrm{Ba}^{2+}$ (Table 1). This trend matched that of the Irving-Williams series (Irving and Williams 1948) with the exception of $\mathrm{Ni}^{2+}$, which would be expected to bind tighter than $\mathrm{Mn}^{2+}$ according to this series. Further, the midpoints for the metal ions that did bind were similar, within sixfold of one another, whereas the midpoints for $\mathrm{Sr}^{2+}$ and $\mathrm{Ba}^{2+}$ were at least two orders of magnitude higher than those for the other metal ions.

\section{Is there "hidden" specificity for the two metal ion binding sites in P4-P6 RNA?}

Despite the enormous simplifications due to the experimental design and detailed knowledge of the RNA system studied, relative to prior studies of RNA metal ion specificity, the results shown in Figure 3 and summarized in Table 1 still represent a potentially complex composite of binding specificities and cooperative effects from the two metal ion sites. We therefore carried out experiments to test whether there were hidden preferences for specific 


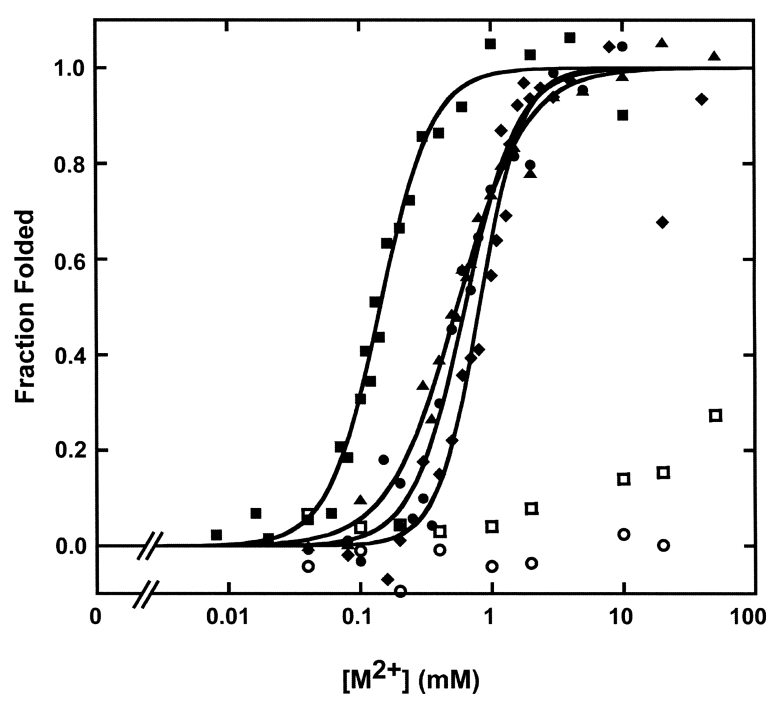

FIGURE 3. Folding of P4-P6 RNA in the presence of $2 \mathrm{M} \mathrm{NaCl}$. Folding was monitored by hydroxyl radical footprinting in the presence of varying amounts of $\mathrm{Mn}^{2+}(\boldsymbol{\square}), \mathrm{Ca}^{2+}(\mathbf{\Lambda}), \mathrm{Mg}^{2+}(\bullet)$, $\mathrm{Ni}^{2+}(\diamond), \mathrm{Sr}^{2+}(\square)$, or $\mathrm{Ba}^{2+}(\bigcirc)$. Residues within the metal ion core show increased protection with increasing divalent ion concentration. Values of folding midpoints and Hill slopes are given in Table 1. $\mathrm{Ba}^{2+}$ could only be used within a limited range, as it caused P4-P6 RNA to precipitate at concentrations below those required to induce a folding transition. Values given for $\mathrm{Ba}^{2+}$ are therefore a lower limit. $\mathrm{Sr}^{2+}$ could not be used at higher concentrations due to solubility limits and also only gives a lower limit.

metal ions at one or the other of the two binding sites or cooperativity specific to distinct sets of metal ions at the two sites.

The general approach can be understood as follows (see Materials and Methods for details of the model used). If different metal ions were to have different specificities for two binding sites on P4-P6, then combinations of metal ions would yield binding at lower concentrations of metal ion mixtures than either metal ion alone. ${ }^{2}$ If instead the relative metal ion affinities for each of the sites were the same, then the concentration of a metal ion mixture needed for occupancy of the sites (and folding) would simply be the average of the $\left[\mathrm{M}^{2+}\right]_{1 / 2}$ values for each metal ion alone, weighted by the ratio of concentrations of the two metal ions.

We first explored potential preferences at individual sites by carrying out mixed metal ion folding experiments titrating mixtures of $\mathrm{Mg}^{2+}$ with $\mathrm{Mn}^{2+}, \mathrm{Ca}^{2+}$, or $\mathrm{Ni}^{2+}$ at a constant ratio, with ratios of $4: 1$ for $\mathrm{Mg}^{2+}$ and $\mathrm{Mn}^{2+}$ (Fig. 4A) and 1:1 for $\mathrm{Mg}^{2+}$ and $\mathrm{Ca}^{2+}$ or $\mathrm{Ni}^{2+}$ (Fig. 4B,C). As above we assayed metal ion binding by its coupling to folding and protection from hydroxyl radical cleavage.

Comparison of the data obtained in the mixed metal ion experiments shown in Figure 4, A-C, with predicted dependencies with or without preferential site binding (see Materials and Methods) revealed that differences of 30-fold for $\mathrm{Mn}^{2+}$ and 10 -fold for $\mathrm{Ca}^{2+}$ and $\mathrm{Ni}^{2+}$ would be readily detectable (Fig. 4A-C, dashed lines). ${ }^{2}$ Fits of the experimental data with a preferential site binding model resulted in poor $\mathrm{r}^{2}$ values: 0.872 for the $\mathrm{Mn}^{2+} / \mathrm{Mg}^{2+}$ data with a 30-fold preference, 0.908 for the $\mathrm{Ca}^{2+} / \mathrm{Mg}^{2+}$ data with a 10 -fold preference, and 0.891 for the $\mathrm{Ni}^{2+} / \mathrm{Mg}^{2+}$ data with a 10 -fold preference. By comparison, the fits without preferential site binding resulted in $r^{2}$ values of 0.984 for the $\mathrm{Mn}^{2+} / \mathrm{Mg}^{2+}$ combination, 0.984 for the $\mathrm{Ca}^{2+} / \mathrm{Mg}^{2+}$ combination, and 0.994 for the $\mathrm{Ni}^{2+} / \mathrm{Mg}^{2+}$ combination. Thus, the similar values of $\left[\mathrm{M}^{2+}\right]_{1 / 2}$ obtained in the mixed metal ion titrations of Figure 4, A-C, suggest that there is no large differential specificity at the two binding sites.

It is important to recognize that, although the two metal ions bind cooperatively and this binding is coupled to folding, the results nonetheless speak to the binding preferences of each of the two binding sites individually. That is, as shown in Scheme 2, the energy required to fold can, in principle, be thermodynamically parsed from the energies for binding the metal ions in the two sites. While one cannot parse these energies in practice, the experiments herein are comparative in their nature-we are assessing the relative ability of different metal ions to occupy the sites. The results, as analyzed above, indicate that there is no strong preference for the metal ions $\mathrm{Mn}^{2+}, \mathrm{Ca}^{2+}$, and $\mathrm{Ni}^{2+}$ relative to $\mathrm{Mg}^{2+}$ for either of the two specific metal ion sites in P4-P6.

It is important to further consider the results of Figure 4, $\mathrm{A}-\mathrm{C}$, in terms of cooperativity of metal ion binding. There is binding cooperativity - the structure probing results indicate that local folding is coupled to binding of two metal ions (i.e., Hill slope of 2), and there is no detectable binding of just one metal ion. Nevertheless, as above, we can assess whether there are differences in cooperativity with different combinations of metal ions, relative to having $\mathrm{Mg}^{2+}$ occupy both metal ion sites. If, for example,

\footnotetext{
${ }^{2}$ To obtain the relative affinities at the two sites, it was assumed that one site has a preference of three-, 10-, or 30-fold, and the affinity for the test ion at the second site was adjusted by the same factor in the opposite direction to reproduce the observed folding midpoint for the titration with that metal ion alone. For example, if one site has a threefold preference for $\mathrm{Ca}^{2+}$, the other site would have a threefold decrease in affinity for $\mathrm{Ca}^{2+}$. For ions with similar affinity in single ion titrations (for example, $\mathrm{Mg}^{2+}$, $\mathrm{Ca}^{2+}$, and $\mathrm{Ni}^{2+}$ ), this procedure results in one site having a preference for one ion and the other site having a preference for the other ion. When both ions are present, each binds to its preferred site, resulting in folding at a total ion concentration lower than would be seen for either ion on its own. The equation used to generate the expected plots for threefold, 10fold, and 30-fold preferences for one ion (Equation 8) is analogous to Equation 7, except that the affinity at each specific metal ion site was treated independently. In this equation, M1 and M2 are the two ions being mixed in the titration, $\mathrm{A}$ and $\mathrm{B}$ refer to the two specific metal ion binding sites, and $\mathrm{K}_{\mathrm{M} 1}{ }^{\mathrm{A}}, \mathrm{K}_{\mathrm{M} 1}{ }^{\mathrm{B}}, \mathrm{K}_{\mathrm{M} 2}{ }^{\mathrm{A}}$, and $\mathrm{K}_{\mathrm{M} 2}{ }^{\mathrm{B}}$ refer to the affinities of each ion for each of the two binding sites.
}

$$
\text { Fraction folded }=\frac{\frac{[M 1]^{2}}{K_{M 1}^{A} K_{M 1}^{B}}+\frac{[M 2]^{2}}{K_{M 2}^{A} K_{M 2}^{B}}+\frac{[M 1][M 2]}{K_{M 1}^{A} K_{M 2}^{B}}+\frac{[M 1][M 2]}{K_{M 2}^{A} K_{M 1}^{B}}}{1+\frac{[M 1]^{2}}{K_{M 1}^{A} K_{M 1}^{B}}+\frac{[M 2]^{2}}{K_{M 2}^{A} K_{M 2}^{B}}+\frac{[M 1][M 2]}{K_{M 1}^{A} K_{M 2}^{B}}+\frac{[M 1][M 2]}{K_{M 2}^{A} K_{M 1}^{B}}}
$$


TABLE 1. Metal ion affinities for P4-P6 RNA and properties

\begin{tabular}{lccccc}
\hline $\mathrm{M}^{2+}$ identity & {$\left[\mathrm{M}^{2+}\right]_{1 / 2}(\mathrm{mM})$} & $\mathrm{n}^{\mathrm{a}}$ & $\begin{array}{c}\text { Hydration } \\
\text { number }^{b}\end{array}$ & $\begin{array}{c}\text { lonic } \\
\text { radius }(\AA)^{\mathrm{c}}\end{array}$ & $\begin{array}{c}\text { Absolute } \\
\text { hardness }^{\mathrm{d}}\end{array}$ \\
\hline $\mathrm{Mn}^{2+}$ & $0.14 \pm 0.004$ & $2.2 \pm 0.2$ & 6 & $0.67-0.83^{\mathrm{e}}$ & 9.02 \\
$\mathrm{Mg}^{2+}$ & $0.63 \pm 0.04$ & $2.2 \pm 0.3$ & 6 & 0.72 & 32.55 \\
$\mathrm{Ca}^{2+}$ & $0.55 \pm 0.02$ & $1.7 \pm 0.1$ & 8 & 1.12 & 19.52 \\
$\mathrm{Ni}^{2+}$ & $0.81 \pm 0.05$ & $2.7 \pm 0.4$ & 4 & $0.55-0.66^{\mathrm{f}}$ & 8.5 \\
$\mathrm{Ba}^{2+}$ & $>20$ & $\mathrm{~N} / \mathrm{A}$ & 6 & 1.35 & - \\
$\mathrm{Sr}^{2+}$ & $>50$ & $\mathrm{~N} / \mathrm{A}$ & 6 & 1.18 & 16.3 \\
\hline
\end{tabular}

${ }^{a}$ Errors given are likely underestimates of the actual uncertainty in the Hill slope. The value of $r^{2}$, an estimate of the goodness of fit, for the fits with the values for $n_{H}$ shown here are $0.992,0.979,0.991$, and 0.971 for $\mathrm{Mn}^{2+}, \mathrm{Mg}^{2+}, \mathrm{Ca}^{2+}$, and $\mathrm{Ni}^{2+}$, respectively. With the value of $n_{H}$ fixed at 2, the corresponding values of $r^{2}$ are 0.991, 0.978, 0.988, and 0.965, respectively, each negligibly smaller. With the value of $n_{H}$ fixed at 2 , the corresponding values of $\left[\mathrm{M}^{2+}\right]_{1 / 2}$ are $0.14,0.64,0.55$, and $0.78 \mathrm{mM}$ for $\mathrm{Mn}^{2+}, \mathrm{Mg}^{2+}, \mathrm{Ca}^{2+}$, and $\mathrm{Ni}^{2+}$, respectively, not significantly different than the values in the table.

${ }^{b}$ Data from Feig and Uhlenbeck (1999).

'Data from Shannon (1976). Ionic radius varies depending on hydration number, and the radius for the most common species is indicated here. In general, ionic radius increases with higher hydration number.

${ }^{\mathrm{d}} \mathrm{A}$ property that reflects the covalent character in a metal-ligand bond. Data from Pearson (1988) and Feig and Uhlenbeck (1999).

${ }^{\mathrm{e}}$ Ionic radius depends on spin state of ion.

flonic radius depends on geometry.

Finally, to control for the possibility that $\mathrm{Sr}^{2+}$ might interfere with $\mathrm{Mg}^{2+}$ dependent folding, we also titrated $\mathrm{Sr}^{2+}$ into a solution containing P4-P6 in $2 \mathrm{M}$ $\mathrm{NaCl}$ and $1.5 \mathrm{mM} \mathrm{Mg}^{2+}$. In this case, there was no unfolding or alternative conformation indicated by the hydroxyl radical protection pattern of P4-P6 (not shown). This result suggests that $\mathrm{Sr}^{2+}$ has a very low affinity for the metal ion core of P4-P6. Thus, we conclude that $\mathrm{Sr}^{2+}$ and $\mathrm{Ba}^{2+}$ are excluded from both metal ion binding sites, relative to $\mathrm{Mg}^{2+}, \mathrm{Mn}^{2+}, \mathrm{Ca}^{2+}$, and $\mathrm{Ni}^{2+}$.

The absence of folding by $\mathrm{Sr}^{2+}$ or $\mathrm{Ba}^{2+}$ alone, and $\mathrm{Sr}^{2+}$ or $\mathrm{Ba}^{2+}$ in the presence of $\mathrm{Mg}^{2+}$, also argues against a mechanism for folding in which divalent ions that accumulate in the ion atmosphere cause or stimulate the folding transition. If, even in the presence of $2 \mathrm{M} \mathrm{NaCl}$, folding were induced by accumulation of divalent metal ions in the ion atmosphere, then both $\mathrm{Sr}^{2+}$ and

$\mathrm{Mg}^{2+}$ increased the binding affinity of $\mathrm{Ca}^{2+}$ more than it increased the binding of a second $\mathrm{Mg}^{2+}$, a lower midpoint would have been observed with the metal ion mixture. Such a decrease would correspond to an increased cooperativity for the $\mathrm{Mg}^{2+} / \mathrm{Ca}^{2+}$ pair relative to $\mathrm{Mg}^{2+} / \mathrm{Mg}^{2+}$. As no effect was observed, we can conclude that there is no large difference in cooperativity for the different metal ion pairs. This result is the simplest expectation given the similar $\left[\mathrm{M}^{2+}\right]_{1 / 2}$ values for each of these metal ions alone.

A related strategy was employed to probe whether the weak $\mathrm{Sr}^{2+}$ and $\mathrm{Ba}^{2+}$ effects resulted from exclusion from only one site. As we know that $\mathrm{Mg}^{2+}$ can occupy both sites, we added $\mathrm{Mg}^{2+}$ at a concentration just below its folding midpoint $\left(0.2 \mathrm{mM}\right.$ added, compared with a $\left[\mathrm{Mg}^{2+}\right]_{1 / 2}$ of $0.6 \mathrm{mM}$ ) in the presence of $2 \mathrm{M} \mathrm{NaCl}$, as above. We then titrated in increasing concentrations of $\mathrm{Ba}^{2+}$ (Fig. 5A) or $\mathrm{Sr}^{2+}$ (Fig. 5B) to determine if folding could now be induced by having $\mathrm{Mg}^{2+}$ bound at one site and $\mathrm{Sr}^{2+}$ or $\mathrm{Ba}^{2+}$ bound at the other. In neither case was folding rescued. We also tested the possibility that the relatively small $\mathrm{Mg}^{2+}$ ion bound at one site induced a conformation that could not accommodate the larger $\mathrm{Sr}^{2+}$ ion at the other site, whereas an alternative structure that could accommodate $\mathrm{Sr}^{2+}$ might be established with a larger ion such as $\mathrm{Ca}^{2+}$. This test was carried out by adding $\mathrm{Ca}^{2+}$ at $0.6 \mathrm{mM}$ (the midpoint for folding in the presence of $\mathrm{Ca}^{2+}$ alone) and adding increasing amounts of $\mathrm{Sr}^{2+}$. No further folding was observed (data not shown), suggesting that the lack of folding due to $\mathrm{Sr}^{2+}$ was not specific to a structure induced by a particular starting ion. Thus, $\mathrm{Sr}^{2+}$ and $\mathrm{Ba}^{2+}$ are excluded from both binding sites in P4-P6 RNA.
$\mathrm{Ba}^{2+}$ would be expected to induce folding of the A-rich bulge, as their ability to enter the ion atmosphere and screen charge is similar to that of $\mathrm{Mg}^{2+}$ and the other divalent metal ions (Y. Bai, V.B. Chu, J. Lipfert, V. Pande, S. Doniach, and D. Herschlag, in prep.). This observation is consistent with the measurement of substantial metal ion core folding under $2 \mathrm{M} \mathrm{Na}^{+}$conditions that give $<1 \mathrm{Mg}^{2+}$ associated with the ion atmosphere (Das et al. 2005b) and with the ability of atomic-level changes in the putative metal ion ligands to alter $\mathrm{M}^{2+}$-induced folding in $2 \mathrm{M} \mathrm{Na}^{+}$ (J. Frederiksen, R. Das, D. Herschlag, and J. Piccirilli, in prep.).

\section{DISCUSSION}

We have reported a direct observation of metal ion site specificity in natural RNA metal ion binding sites. The tested divalents fall into two classes: ions that are capable of folding P4-P6 and those that are not, at least up to the physical limits imposed by ion solubility. Among the ions that bind the metal ion core of P4-P6, there is little specificity: $\mathrm{Mg}^{2+}, \mathrm{Mn}^{2+}, \mathrm{Ca}^{2+}$, and $\mathrm{Ni}^{2+}$ bind with similar affinity. This similarity occurs despite the wide variation in size, preferred hydration number, and hardness of these metal ions (Table 1). This degree of accommodation is greater than often observed for protein metal ion binding sites. It is likely that the low specificity of the RNA metal ion binding sites relative to many protein sites derives at least in part from the presence of only oxygen ligands in the RNA metal ion core. In all cases, oxygen ligands from solvating water molecules are swapped for oxygen ligands 
A

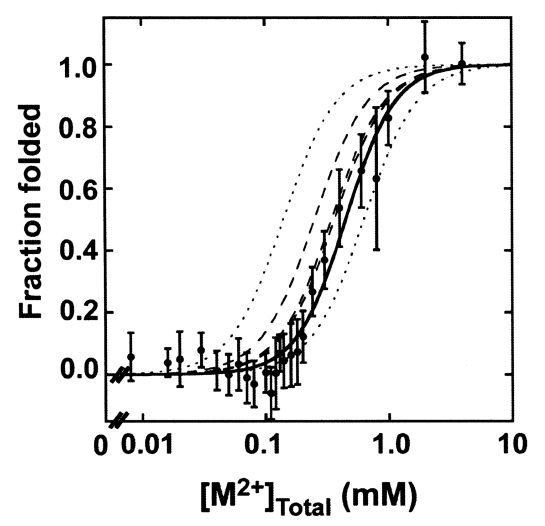

C

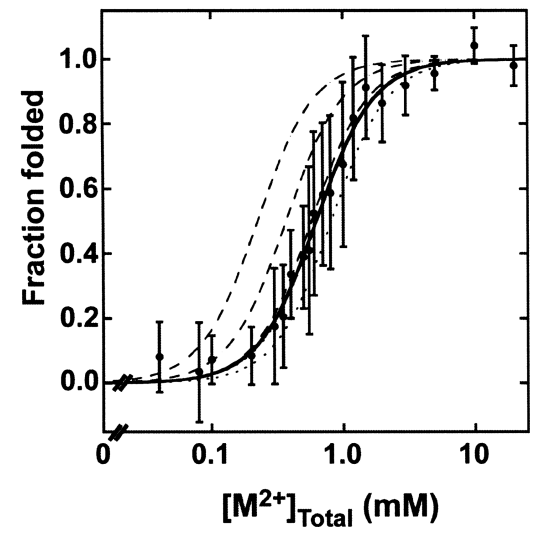

FIGURE 4. Folding of P4-P6 RNA in the presence of $2 \mathrm{M} \mathrm{NaCl}$ and mixtures of divalent ions to test preferential binding to one of the two metal ion binding sites. Each plot shows data obtained from hydroxyl radical footprinting experiments as a function of total divalent ion. In addition, each panel contains predicted data for a two-metal site system, in which one of the two sites exhibits a preference for one metal ion, relative to the $\mathrm{Mg}^{2+}$ affinity. See text for further details of this model. Use of these specificity factors and the observed $\left[\mathrm{M}^{2+}\right]_{1 / 2}$ values for each metal alone determines the predicted curves (dashed lines) for threefold, 10fold, and 30-fold preferences. The predicted curves shift further to the left as the preferential affinity for one site increases. For comparison, each plot also contains the best fit to the data set for $\mathrm{Mg}^{2+}$ alone and the second metal ion alone (dotted lines). (In $C$, the dotted line representing the folding transition in $\mathrm{Mg}^{2+}$ alone is on top of the line representing the folding transition in a mixture of $\mathrm{Mg}^{2+}$ and $\mathrm{Ni}^{2+}$, and therefore cannot be seen). (A) Folding was monitored in the presence of a mixture of $\mathrm{MgCl}_{2}$ and $\mathrm{MnCl}_{2}$, at a constant ratio of 4:1. The folding midpoint occurred at $0.45 \pm 0.04 \mathrm{mM}$ total divalent ion, with $\mathrm{n}_{\mathrm{H}}=2.1$. Fits with the preferential site binding model have $\mathrm{r}^{2}$ values of $0.970,0.962$, and 0.872 for the model with threefold, 10 -fold, and 30-fold preference at one site, respectively, while the fit shown here has an $r^{2}$ value of 0.984. (B) Folding was monitored in the presence of a mixture of $\mathrm{MgCl}_{2}$ and $\mathrm{CaCl}_{2}$ at a constant ratio of $1: 1$. The folding midpoint was at $0.52 \pm 0.05 \mathrm{mM}$, with a value of $n_{H}=1.4$. Fits with the preferential site binding model have $r^{2}$ values of 0.974 , 0.908 , and 0.672 for the model with threefold, 10 -fold, and 30 -fold preference at one site, respectively, while the fit shown here has an $\mathrm{r}^{2}$ value of 0.984. (C) Folding was monitored in the presence of a mixture of $\mathrm{MgCl}_{2}$ and $\mathrm{NiCl}_{2}$ at a constant ratio of 1:1. The folding midpoint was at $0.63 \pm 0.03 \mathrm{mM}$ total divalent with a value of $\mathrm{n}_{\mathrm{H}}=2.0$. Fits with the preferential site binding model have $\mathrm{r}^{2}$ values of $0.992,0.891$, and 0.605 for the model with threefold, 10 -fold, and 30 -fold preference at one site, respectively, while the fit shown here has an $\mathrm{r}^{2}$ value of 0.994 at these binding sites so that intrinsic atomic preferences of metal ions, which can contribute greatly to specificity, do not contribute at these sites. Ironically, the $\left[\mathrm{M}^{2+}\right]_{1 / 2}$ values for $\mathrm{Mg}^{2+}$ and $\mathrm{Mn}^{2+}$, which are most similar in size and properties, differ by about fourfold. We do not understand the origin of the modest preference for $\mathrm{Mn}^{2+}$. It may result from additional interactions with the P4-P6 RNA at sites other than the metal ion core; $\mathrm{Mn}^{2+}$ has a higher affinity for the N7 of purines than do alkaline earth ions (Duguid et al. 1995).

Although $\mathrm{Mg}^{2+}, \mathrm{Mn}^{2+}, \mathrm{Ca}^{2+}$, and $\mathrm{Ni}^{2+}$ all bind with similar affinity, there is substantial discrimination against $\mathrm{Sr}^{2+}$ and $\mathrm{Ba}^{2+}$, the two largest metal ions probed (Table 1). A possible model is as follows. The P4-P6 metal ion core has substantial flexibility due to the limited packing density in RNA and the multiple degrees of freedom of the RNA backbone. Thus, the sites can accommodate divalent cations of different sizes and different geometrical preferences. Nevertheless, there are limits to the adaptability of these sites, and metal ions that are larger than a certain threshold allowed by the RNA's malleability are strongly discriminated against. This model requires a sharp threshold, as $\mathrm{Ca}^{2+}$ and $\mathrm{Sr}^{2+}$ are similar in size (1.12 $\AA$ and $1.18 \AA$, respectively), and yet $\mathrm{Ca}^{2+}$ is able to fold P4-P6 at concentrations at least two orders of magnitude lower than $\mathrm{Sr}^{2+}$. Alternatively or in addition, charge density may be a critical feature with the larger, less charge dense metal ions interacting less well with the highly charged phosphoryl oxygen atoms that are localized at the metal ion binding sites.

Our understanding of metal ion/RNA interactions and of the energetic rules that govern affinities and specificities is in its infancy. We expect that the approaches outlined herein that allow more incisive investigation of metal ion binding sites in RNA will provide important physical insights into these and other metal ion binding and folding systems. Future studies will allow the generality of the initial observations herein and the models proposed to be tested and 
A

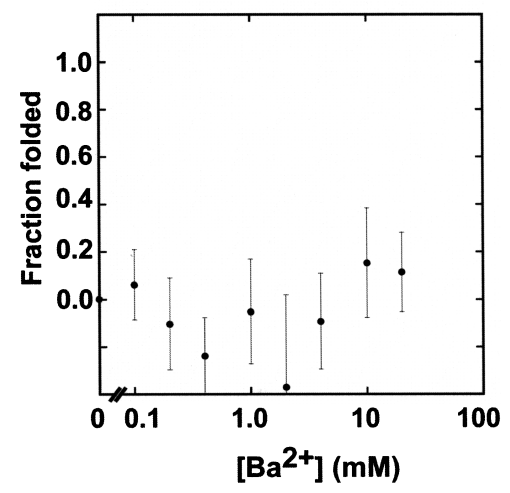

B

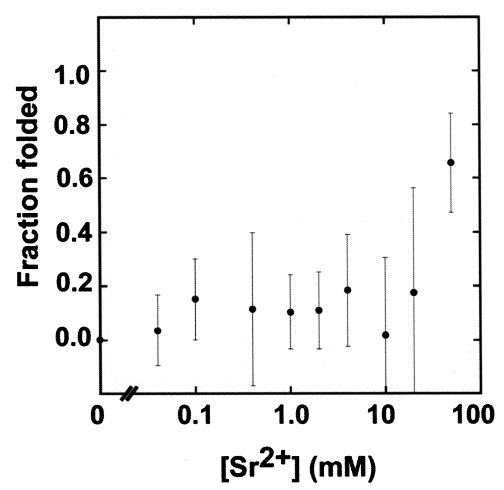

FIGURE 5. Folding of P4-P6 RNA in the presence of $2 \mathrm{M} \mathrm{NaCl}$ and mixtures of divalent ions to test $\mathrm{Ba}^{2+}$ or $\mathrm{Sr}^{2+}$ binding to one site only. Each plot shows data obtained from hydroxyl radical footprinting. In a background of $0.2 \mathrm{mM} \mathrm{MgCl}$, folding was monitored by hydroxyl radical footprinting in the presence of varying amounts of $\mathrm{BaCl}_{2}(A)$ or $\mathrm{SrCl}_{2}(B)$.

refined. Furthermore, these approaches may prove valuable in dissecting the properties of RNAs, or "riboswitches," that act as natural magnesium sensors (Brantl 2006).

\section{MATERIALS AND METHODS}

\section{RNA preparation}

P4-P6 RNA was obtained by in vitro transcription using PCRgenerated DNA templates, and purified by denaturing polyacrylamide gel electrophoresis (PAGE). Purified RNA was radiolabeled at the $5^{\prime}$-end using $\gamma-{ }^{32} \mathrm{P}$-ATP in a T4 polynucleotide kinasemediated reaction. Radiolabeled products were again purified by denaturing PAGE, and buffer-exchanged into doubly distilled water by gel filtration in Microspin columns (Bio-Rad).

\section{Hydroxyl radical footprinting}

Data were collected as in (Das et al. 2005b). Briefly, $5^{\prime}{ }_{-}^{32} \mathrm{P}$-labeled P4-P6 RNA was incubated in the presence of $50 \mathrm{mM}$ Na-MOPS, $\mathrm{pH} 7.0,2 \mathrm{M} \mathrm{NaCl}$, and varying amounts of divalent ion. Fenton reagent $\left(0.1 \mathrm{mM} \mathrm{Fe}\left[\mathrm{NH}_{4}\right]_{2}\left[\mathrm{SO}_{4}\right]_{2}, 0.125 \mathrm{mM}\right.$ EDTA, and $10 \mathrm{mM}$ $\mathrm{Na}$-ascorbate) was added to the RNA and incubated for $60 \mathrm{~min}$ at $25^{\circ} \mathrm{C}$, at which point the reaction was quenched by the addition of thiourea ( $100 \mathrm{mM}$ thiourea, $0.1 \%$ bromophenol blue, $0.1 \%$ xylene cyanol). Radical cleavage products were separated on an $8 \%$ polyacrylamide/7.5 M urea denaturing gel and exposed to a Phosphoimager screen overnight. Gels were quantitated by SAFA (Das et al. 2005a). Individual residues within the metal ion core showing protection with increasing divalent ion (typically, residues $169,176,177,180-182,185$, and 187) were normalized to a scale from 0 to 1 and averaged together for the plots shown. Although residues in $\mathrm{P} 4$ are also involved in the formation of tertiary structure through their interaction with the A-rich bulge (Battle and Doudna 2002; Das et al. 2005b), changes in protection of these residues were not assessed in these experiments, as $5^{\prime}$ - and not 3 '-radiolabeled RNA was used. Error bars are not shown for clarity, but are generally \pm 0.1 , and were calculated by comparing the data for each residue with the average for all residues within a given data set.

\section{Site binding model}

The thermodynamic model used here assumes cooperativity in metal ion binding. This assumption is supported by the results in all binding studies presented here, as Hill coefficients $>1$ are observed in all measurements. This assumption requires that only five species exist in a mixed metal ion solution: the unfolded RNA species and four folded RNA species (one with two ions of type A, $R_{A}^{A}$; one with two ions of type $\mathrm{B}, R_{B}^{B}$; and two with one of each ion type, $R_{B}^{A}$ and $R_{A}^{B}$ ). These four folded species are in equilibrium with the unfolded state, with equilibrium constants defined as follows (Equations [2]-[5]):

$$
\left(K_{A A}\right)^{2}=\frac{[U][A]^{2}}{\left[R_{A}^{A}\right]}
$$

$$
\left(K_{B B}\right)^{2}=\frac{[U][B]^{2}}{\left[R_{B}^{B}\right]}
$$

$$
\left(K_{A B}\right)^{2}=\frac{[U][A][B]}{\left[R_{B}^{A}\right]}
$$

$$
\left(K_{B A}\right)^{2}=\frac{[U][B][A]}{\left[R_{A}^{B}\right]}
$$

The fraction folded RNA is calculated as the sum of all folded species over the total amount of RNA:

$$
\text { Fraction folded }=\frac{\left[R_{A}^{A}\right]+\left[R_{B}^{A}\right]+\left[R_{A}^{B}\right]+\left[R_{B}^{B}\right]}{[U]+\left[R_{A}^{A}\right]+\left[R_{B}^{A}\right]+\left[R_{A}^{B}\right]+\left[R_{B}^{B}\right]}
$$

By rearranging Equations (2)-(5), and substituting into Equation (6), we arrive at Equation (7):

$$
\text { Fraction folded }=\frac{\frac{[A]^{2}}{K_{A A^{2}}}+\frac{[B]^{2}}{K_{B B^{2}}}+\frac{[A][B]}{K_{A B^{2}}}+\frac{[B][A]}{K_{B A}{ }^{2}}}{1+\frac{[A]^{2}}{K_{A A^{2}}}+\frac{[B]^{2}}{K_{B B^{2}}}+\frac{[A][B]}{K_{A B^{2}}}+\frac{[B][A]}{K_{B A^{2}}}}
$$




\section{ACKNOWLEDGMENTS}

We thank John Frederiksen and Joe Piccirilli for permission to cite unpublished results and members of the Herschlag laboratory for helpful discussion and critical reading of this manuscript. This work was supported by a Beckman Scholar Award (K.T.) and by NIH Program Project Grant GM066275 (D.H.).

Received March 17, 2007; accepted May 17, 2007.

\section{REFERENCES}

Adams, P.L., Stahley, M.R., Kosek, A.B., Wang, J., and Strobel, S.A. 2004. Crystal structure of a self-splicing group I intron with both exons. Nature 430: 45-50.

Babu, C.S., Dudev, T., Casareno, R., Cowan, J.A., and Lim, C. 2003. A combined experimental and theoretical study of divalent metal ion selectivity and function in proteins: Application to E. coli ribonuclease H1. J. Am. Chem. Soc. 125: 9318-9328.

Basu, S., Rambo, R.P., Strauss-Soukup, J., Cate, J.H., FerreD'Amare, A.R., Strobel, S.A., and Doudna, J.A. 1998. A specific monovalent metal ion integral to the AA platform of the RNA tetraloop receptor. Nat. Struct. Biol. 5: 986-992.

Battle, D.J. and Doudna, J.A. 2002. Specificity of RNA-RNA helix recognition. Proc. Natl. Acad. Sci. 99: 11676-11681.

Brannvall, M., Mikkelsen, N.E., and Kirsebom, L.A. 2001. Monitoring the structure of Escherichia coli RNase P RNA in the presence of various divalent metal ions. Nucleic Acids Res. 29: 1426-1432.

Brantl, S. 2006. Bacterial gene regulation: Metal ion sensing by proteins or RNA. Trends Biotechnol. 24: 383-386.

Bukhman, Y.V. and Draper, D.E. 1997. Affinities and selectivities of divalent cation binding sites within an RNA tertiary structure. J. Mol. Biol. 273: 1020-1031.

Cate, J.H. and Doudna, J.A. 1996. Metal-binding sites in the major groove of a large ribozyme domain. Structure 4: 1221-1229.

Cate, J.H., Gooding, A.R., Podell, E., Zhou, K., Golden, B.L., Kundrot, C.E., Cech, T.R., and Doudna, J.A. 1996. Crystal structure of a group I ribozyme domain: Principles of RNA packing. Science 273: 1678-1685.

Cate, J.H., Hanna, R.L., and Doudna, J.A. 1997. A magnesium ion core at the heart of a ribozyme domain. Nat. Struct. Biol. 4: 553-558.

Celander, D.W. and Cech, T.R. 1991. Visualizing the higher-order folding of a catalytic RNA molecule. Science 251: 401-407.

Chowrira, B.M., Berzal-Herranz, A., and Burke, J.M. 1993. Ionic requirements for RNA binding, cleavage, and ligation by the hairpin ribozyme. Biochemistry 32: 1088-1095.

Creighton, T. 1993. Proteins: Structures and molecular properties. W.H. Freeman and Company, New York.

Dahm, S.C. and Uhlenbeck, O.C. 1991. Role of divalent metal ions in the hammerhead RNA cleavage reaction. Biochemistry 30: 9464-9469.

Das, R., Laederach, A., Pearlman, S.M., Herschlag, D., and Altman, R.B. 2005a. SAFA: Semi-automated footprinting analysis software for high-throughput quantification of nucleic acid footprinting experiments. RNA 11: 344-354.

Das, R., Travers, K.J., Bai, Y., and Herschlag, D. 2005b. Determining the $\mathrm{Mg}^{2+}$ stoichiometry for folding an RNA metal ion core. J. Am. Chem. Soc. 127: 8272-8273.
Draper, D.E. 2004. A guide to ions and RNA structure. RNA 10: 335343.

Duguid, J.G., Bloomfield, V.A., Benevides, J.M., and Thomas Jr., G.J. 1995. Raman spectroscopy of DNA-metal complexes. II. The thermal denaturation of DNA in the presence of $\mathrm{Sr}^{2+}, \mathrm{Ba}^{2+}$, $\mathrm{Mg}^{2+}, \mathrm{Ca}^{2+}, \mathrm{Mn}^{2+}, \mathrm{Co}^{2+}, \mathrm{Ni}^{2+}$, and $\mathrm{Cd}^{2+}$. Biophys. J. 69: 26232641.

Ennifar, E., Walter, P., and Dumas, P. 2003. A crystallographic study of the binding of 13 metal ions to two related RNA duplexes. Nucleic Acids Res. 31: 2671-2682.

Feig, A.L. and Uhlenbeck, O.C. 1999. The role of metal ions in RNA biochemistry. Cold Spring Harbor Laboratory Press, Cold Spring Harbor, New York.

Grosshans, C.A. and Cech, T.R. 1989. Metal ion requirements for sequence-specific endoribonuclease activity of the Tetrahymena ribozyme. Biochemistry 28: 6888-6894.

Guerrier-Takada, C., Haydock, K., Allen, L., and Altman, S. 1986. Metal ion requirements and other aspects of the reaction catalyzed by M1 RNA, the RNA subunit of ribonuclease P from Escherichia coli. Biochemistry 25: 1509-1515.

Heilman-Miller, S.L., Thirumalai, D., and Woodson, S.A. 2001. Role of counterion condensation in folding of the Tetrahymena ribozyme. I. Equilibrium stabilization by cations. J. Mol. Biol. 306: $1157-1166$.

Irving, H. and Williams, R.J.P. 1948. Order of stability of metal complexes. Nature 162: 746-747.

Juneau, K., Podell, E., Harrington, D.J., and Cech, T.R. 2001. Structural basis of the enhanced stability of a mutant ribozyme domain and a detailed view of RNA-solvent interactions. Structure 9: $221-231$.

Misra, V.K. and Draper, D.E. 1999. The interpretation of $\mathrm{Mg}^{2+}$ binding isotherms for nucleic acids using Poisson-Boltzmann theory. J. Mol. Biol. 294: 1135-1147.

Nakano, S., Cerrone, A.L., and Bevilacqua, P.C. 2003. Mechanistic characterization of the HDV genomic ribozyme: Classifying the catalytic and structural metal ion sites within a multichannel reaction mechanism. Biochemistry 42: 2982-2994.

Pearson, R.G. 1988. Absolute hardness: Application in inorganic chemistry. Inorg. Chem. 27: 734-740.

Pley, H.W., Flaherty, K.M., and McKay, D.B. 1994. Three-dimensional structure of a hammerhead ribozyme. Nature 372: 68-74.

Rangan, P. and Woodson, S.A. 2003. Structural requirement for $\mathrm{Mg}^{2+}$ binding in the group I intron core. J. Mol. Biol. 329: 229-238.

Rosenzweig, A.C. 2002. Metallochaperones: Bind and deliver. Chem. Biol. 9: 673-677.

Scott, W.G., Finch, J.T., and Klug, A. 1995. The crystal structure of an all-RNA hammerhead ribozyme: A proposed mechanism for RNA catalytic cleavage. Cell 81: 991-1002.

Shannon, R.D. 1976. Revised effective ionic radii and systematic studies of interatomic distances in halides and chalcogenides. Acta Crystallogr. A 32: 751-767.

Shi, H. and Moore, P.B. 2000. The crystal structure of yeast phenylalanine tRNA at $1.93 \AA$ resolution: A classic structure revisited. RNA 6: 1091-1105.

Takamoto, K., Das, R., He, Q., Doniach, S., Brenowitz, M., Herschlag, D., and Chance, M.R. 2004. Principles of RNA compaction: Insights from the equilibrium folding pathway of the P4-P6 RNA domain in monovalent cations. J. Mol. Biol. 343: 1195-1206. 

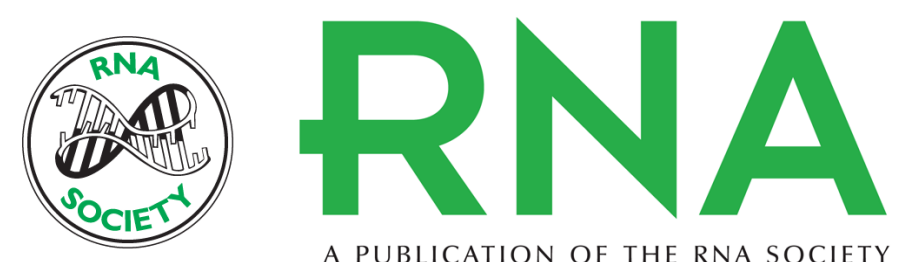

A PUBLICATION OF THE RNA SOCIETY

\section{Low specificity of metal ion binding in the metal ion core of a folded RNA}

Kevin J. Travers, Nathan Boyd and Daniel Herschlag

RNA 2007 13: 1205-1213 originally published online July 6, 2007

Access the most recent version at doi:10.1261/rna.566007

\section{References This article cites 33 articles, 6 of which can be accessed free at: http://rnajournal.cshlp.org/content/13/8/1205.full.html\#ref-list-1}

\section{License}
Email Alerting Receive free email alerts when new articles cite this article - sign up in the box at the Service top right corner of the article or click here.

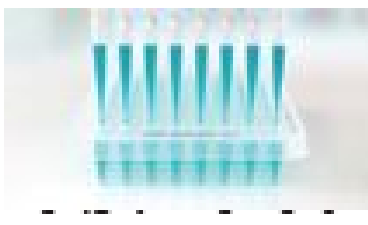

\section{Providing Precise Solutions for} your research.

To subscribe to $R N A$ go to:

http://rnajournal.cshlp.org/subscriptions 